\title{
Synthesis and Characterization of the $N$-Vinylcarbazole-Methyl Methacrylate and $N$-Vinylcarbazole-Methyl Acrylate Copolymer Systems. Thermogravimetric Study
}

\author{
Mercedes IsusI, Matilde RoDRíGuEZ, Idoia LóPEz, \\ and Luis Manuel LEÓN ${ }^{\dagger}$ \\ Departamento de Química Física, Facultad de Ciencias, Universidad del País Vasco (UPV/EHU), \\ Apdo: 644-48080 Bilbao, España
}

(Received March 3, 1997)

\begin{abstract}
Copolymerization of $N$-vinylcarbazole with methyl methacrylate and methyl acrylate has been studied obtaining the reactivity ratios for both systems in tetrahydrofuran. A thermal study of the copolymers related to the $\mathrm{N}$-vinylcarbazole content has been carried out taking into account several theories predicting the dependence of the glass transition temperature on the copolymer composition.

KEY WORDS Copolymer / Glass Transition Temperature / Thermal Stability /
\end{abstract}

$\operatorname{Poly}(N$-vinylcarbazole) (PNVC), is a very interesting polymer due to its electrical and photoconductive properties. $^{1-3}$ However, it has a high glass transition temperature $\left(T_{\mathrm{g}} \approx 490 \mathrm{~K}\right)$. The glass transition is of special importance in polymer field as it reflects the flexibility of the polymer chain and therefore, it limits the possible applications of the material. The high $T_{\mathrm{g}}$ of PNVC makes necessary the use of high processing temperatures which often cause polymer degradation. Low $T_{\mathrm{g}}$ polymeric materials could be synthetized by using comonomers of relatively low $T_{\mathrm{g}}$. These copolymers would be able to maintain some of the PNVC relevant properties specially if they are doped with small electron-acceptor molecules as reported by other authors. ${ }^{2-4}$

The main of this paper concentrates on the study of thermal properties of copolymers. Copolymerization of $N$-vinylcarbazole (NVC) with methyl methacrylate (MMA) and with methyl acrylate (MA) has been carried out, where the homopolymers $T_{\mathrm{g}}$ reached values of $391 \mathrm{~K}$ and $262 \mathrm{~K}$, respectively. The copolymerization process has been studied for both systems and the $T_{\mathrm{g}}$ experimental values of all the synthetized samples have been measured. The prediction of the variation of $T_{\mathrm{g}}$ with the copolymer composition has been attempted by several authors ${ }^{5-7}$ and some of these models have been applied to our systems. Moreover, the possible practical applications of these materials are directly related to their thermal stability and so, this paper also focuses on the study of the thermal degradation of these copolymers as a function of their composition.

\section{EXPERIMENTAL}

NVC (Fluka) prior to dry in a vacuum line and store in the dark, it was recrystallized several times from hot methanol under dry nitrogen.

MMA, and MA (Fluka) were dried over calcium hydride and fractionally distilled under vacuum.

$\alpha, \alpha^{\prime}$-Azobisisobutyronitrile (AIBN) (Fluka) was recrystallized from diethyl ether.

Methanol (Scharlau) and tetrahydrofuran (THF)

\footnotetext{
$\uparrow$ To whom correspondence should be addressed.
}

(Scharlau) were purified by standard procedures.

The copolymerization study was extended to cover all the range of monomer feed compositions. The copolymerization reactions were carried out using $\mathrm{THF}$ as solvent and AIBN as initiator which concentration was $0.1 \%$ by mole in relation to the total monomer. The desired amount of the required reagents was added to the reaction flask which was evacuated by several freeze-thaw cycles and then, sealed under vacuum and placed in a thermostatic bath at $323 \mathrm{~K}$.

The copolymer was isolated by precipitation into methanol and then reprecipitated from a THF solution into an excess of hot methanol. Finally, the copolymer was dried in a vacuum line at room temperature for $48 \mathrm{~h}$.

The amount of nitrogen contained in the copolymers was determined by elemental analysis and from it, the copolymer composition was obtained. A Perkin Elmer Elemental Analyzer CHN 2400 was used.

The molecular weight of the copolymers (referred to polystyrene equivalents) was obtained by gel permeation chromatography (GPC) using a Waters Chromatograph with THF as solvent at $298 \mathrm{~K}$. Two Shodex columns with an exclusion limit of $5 \times 10^{7}$ were used. A previous calibration with standard polystyrene samples was performed.

The glass transition temperature measurements were carried out in a Perkin Elmer DSC-4 Calorimeter with a heating rate of $20^{\circ} \mathrm{C} \mathrm{min}^{-1}$.

Thermogravimetric degradations were measured using a Perkin Elmer TGS-2 Thermobalance. A standard dynamic heating procedure was followed from room temperature to $873 \mathrm{~K}$ (heating rate $=10^{\circ} \mathrm{C} \mathrm{min}^{-1}$ ). Samples of $6-7 \mathrm{mg}$ and a stream of dry nitrogen were used.

\section{RESULTS AND DISCUSSION}

The reaction conditions, monomer feed, copolymer composition, molecular weight, polydispersity $(I)$, and $T_{\mathrm{g}}$ values are fully detailed on Tables I and II. The Figure 1 shows the relationship between the mole fraction of NVC in the copolymer $\left(F_{1}\right)$ and the mole fraction in the monomer feed $\left(f_{1}\right)$ for both systems.

Analysis of the experimental monomer feed ratios 
M. ISUSI et al.

Table I. Copolymerization of NVC with MMA and copolymer characteristics

\begin{tabular}{|c|c|c|c|c|c|c|c|}
\hline \multirow{2}{*}{ Sample } & \multirow{2}{*}{$\begin{array}{c}\begin{array}{c}\text { Monomer } \\
\text { feed }\end{array} \\
\text { mol\% NVC }\end{array}$} & \multirow{2}{*}{$\frac{\begin{array}{c}\text { Polym. } \\
\text { time }\end{array}}{\min }$} & \multirow{2}{*}{$\frac{\text { Conv. }}{w t \%}$} & \multirow{2}{*}{$\begin{array}{c}\begin{array}{c}\text { Copolymer } \\
\text { comp. }\end{array} \\
\text { mol\% NVC }\end{array}$} & \multirow{2}{*}{$\frac{M_{n} \times 10^{-4}}{\mathrm{~g} \mathrm{~mol}^{-1}}$} & \multirow{2}{*}{$I$} & \multirow{2}{*}{$\frac{T_{\mathrm{g}}}{\mathrm{K}}$} \\
\hline & & & & & & & \\
\hline PMMA & 0 & 480 & 12.1 & 0 & 32.4 & 1.53 & 391 \\
\hline MMANVC7 & 10 & 420 & 13.3 & 4.08 & 17.5 & 1.61 & 402 \\
\hline MMANVC8 & 20 & 360 & 15.3 & 8.31 & 17.6 & 2.06 & 408 \\
\hline MMANVC5 & 35 & 330 & 8.23 & 14.4 & 21.9 & 1.58 & - \\
\hline MMANVC1 & 50 & 320 & 7.41 & 23.0 & 28.2 & 1.83 & 419 \\
\hline MMANVC6 & 65 & 300 & 14.8 & 31.6 & 24.3 & 1.95 & - \\
\hline MMANVC3 & 80 & 180 & 8.60 & 40.8 & 17.4 & 2.22 & 442 \\
\hline MMANVC4 & 90 & 118 & 11.4 & 53.5 & 28.0 & 1.79 & 450 \\
\hline PNVC & 100 & 150 & 15.2 & 100 & 1.80 & 1.59 & 486 \\
\hline
\end{tabular}

Table II. Copolymerization of NVC with MA and copolymer characteristics

\begin{tabular}{|c|c|c|c|c|c|c|c|}
\hline \multirow{2}{*}{$\begin{array}{c}\text { Sample } \\
\text { name }\end{array}$} & \multirow{2}{*}{$\frac{\begin{array}{c}\text { Monomer } \\
\text { feed }\end{array}}{\text { mol\% NVC }}$} & \multirow{2}{*}{$\frac{\begin{array}{c}\text { Polym. } \\
\text { time }\end{array}}{\text { min }}$} & \multirow{2}{*}{$\frac{\text { Conv. }}{w t \%}$} & \multirow{2}{*}{$\begin{array}{c}\begin{array}{c}\text { Copolymer } \\
\text { comp. }\end{array} \\
\mathrm{mol} \% \mathrm{NVC}\end{array}$} & \multirow{2}{*}{$\frac{M_{n} \times 10^{-3}}{\mathrm{~g} \mathrm{~mol}^{-1}}$} & \multirow{2}{*}{$I$} & \multirow{2}{*}{$\frac{T_{\mathrm{g}}}{\mathrm{K}}$} \\
\hline & & & & & & & \\
\hline PMA & 0 & 300 & 12.3 & 0 & - & - & 262 \\
\hline MANVC4 & 10 & 60 & 16.5 & 11.1 & 44.4 & 1.61 & 292 \\
\hline MANVC2 & 20 & 72 & 18.7 & 20.0 & 45.9 & 1.86 & 295 \\
\hline MANVC5 & 40 & 60 & 21.4 & 31.6 & 33.2 & 1.67 & 365 \\
\hline MANVCl & 50 & 60 & 13.6 & 36.0 & 27.8 & 1.60 & 348 \\
\hline MANVC7 & 70 & 64 & 22.7 & 44.3 & 29.1 & 1.66 & 370 \\
\hline MANVC3 & 80 & 65 & 14.3 & 48.4 & 66.0 & 1.82 & 386 \\
\hline MANVC6 & 90 & 60 & 13.4 & 57.8 & 60.5 & 1.50 & 418 \\
\hline PNVC & 100 & 150 & 15.2 & 100 & 18.0 & 1.59 & 486 \\
\hline
\end{tabular}

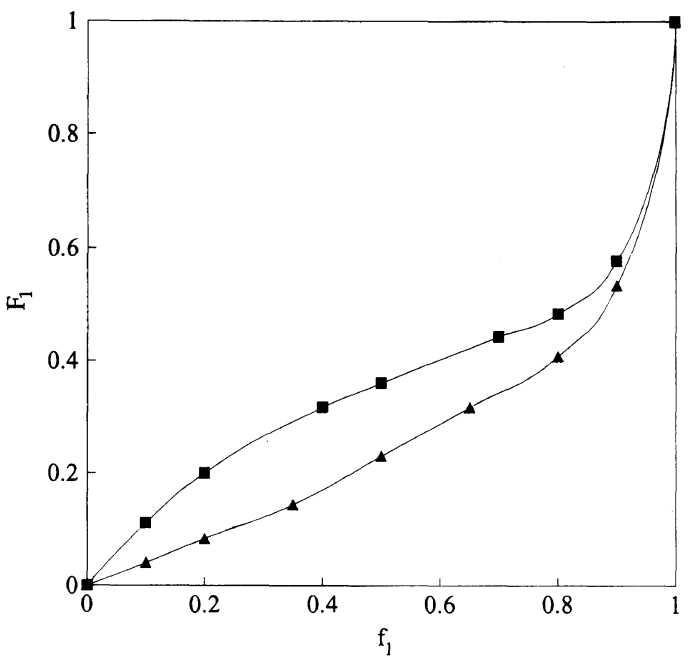

Figure 1. Copolymerization diagrams of NVC-MMA (A) and NVC-MA (ם) systems.

together with the copolymer compositions allow the calculation of the reactivity ratios for each pair of monomers. Due to the absence of charge transfer complexes in these systems, the reactivity ratios have been calculated assuming that the terminal model for free radical copolymerization proposed by Mayo and Lewis $^{8}$ is applicable to the data under consideration. This model postulates that the addition rate of a monomer to a growing polymer chain is independent of the chain length and depends only on the nature of the terminal radical unit. The copolymer composition equation for this model is:

$$
F_{1}=\frac{r_{1} f_{1}^{2}+f_{1} f_{2}}{r_{1}{f_{1}}^{2}+2 f_{1} f_{2}+r_{2} f_{2}{ }^{2}}
$$

where $f_{1}$ and $f_{2}$ are, respectively, the mole fraction of monomer $\mathrm{M}_{1}$ and $\mathrm{M}_{2}$ in the feed, $F_{1}$ is the mole fraction of $\mathrm{M}_{1}$ in the copolymer, $r_{1}$ and $r_{2}$ are the monomer reactivity ratios.

The calculation of $r_{1}$ and $r_{2}$ requires firstly to accomplish several copolymerization reactions at low conversions with different monomeric compositions in the feed, and secondly, the analysis of the monomeric composition in the copolymer.

Several methods ${ }^{9,10}$ can be used to linearize the composition equation. Taking into account that proposed by Kelen and Tüdos, ${ }^{10}$ the copolymer composition equation can be rearranged by defining the variables:

$$
G=\frac{f_{1}}{f_{2}}\left[\frac{F_{1}-F_{2}}{F_{1}}\right] \text { and } F=\left[\frac{f_{1}}{f_{2}}\right]^{2} \frac{F_{2}}{F_{1}}
$$

So the eq 1 can be written as follows:

$$
\frac{G}{\alpha+F}=\left(r_{1}+\frac{r_{2}}{\alpha}\right) \frac{F}{\alpha+F}-\frac{r_{2}}{\alpha}
$$

Where $\alpha$ denotes an arbitrary constant $(\alpha>0)$ given by:

$$
\alpha=\sqrt{F_{\mathrm{MAX}} \cdot F_{\mathrm{MIN}}}
$$

Being $F_{\mathrm{MAX}}$ and $F_{\mathrm{MIN}}$ the maximum and minimum values of $F$, respectively.

By introducing: 


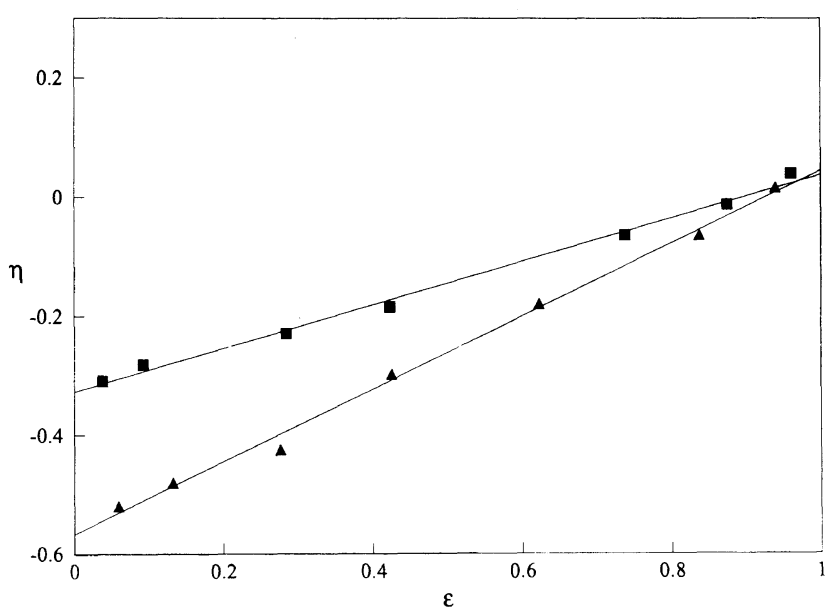

Figure 2. Kelen-Tüdos plots for NVC-MMA (A) and NVC-MA (ם) systems.

$$
\eta=\frac{G}{\alpha+F} \quad \text { and } \quad \varepsilon=\frac{F}{\alpha+F}
$$

the eq 3 transforms into:

$$
\eta=\left(r_{1}+\frac{r_{2}}{\alpha}\right) \varepsilon-\frac{r_{2}}{\alpha}
$$

which allows the calculation of the reactivity ratios from the copolymers composition data. Figure 2 shows the straight lines obtained for the two systems and their respective $r_{1}$ and $r_{2}$ values are:

$$
\begin{array}{ll}
\text { NVC-MMA copolymer } & \text { NVC-MA copolymer } \\
r_{1}=0.045 & r_{1}=0.037 \\
r_{2}=2.56 & r_{2}=0.79 \\
r_{1} r_{2}=0.114 & r_{1} r_{2}=0.029
\end{array}
$$

These values suggest that the copolymers have an alternating character. The reactivity ratios obtained for the NVC-MMA system are in agreement with those reported by Curteanu et al. ${ }^{11}$ using benzene as solvent at $343 \mathrm{~K}$, and those recalculated by this author from previous data found for this system. ${ }^{12-14}$

\section{Glass Transition Temperature}

Effect of the Copolymer Composition. The glass transition temperatures for both systems are shown on Tables I and II. Despite the great difference observed between $r_{1}$ and $r_{2}$ in both systems, there is no microphase separation in the bulk state because all the samples show a single glass transition at the temperature range given by the $T_{\mathrm{g}}$ of the respective homopolymers. As it can be seen, the higher the NVC content in the copolymer, the higher the $T_{\mathrm{g}}$. The possible prediction of the glass transition temperatures as a function of the copolymer composition has been considered by the application of several theories.

Fox ${ }^{5}$ first proposed an additive relation:

$$
\frac{1}{T_{\mathrm{g}}}=\frac{w_{1}}{T_{\mathrm{g} 1}}+\frac{w_{2}}{T_{\mathrm{g} 2}}
$$

where $w_{1}$ and $w_{2}$ are the NVC and the respective comonomer weight fractions in the copolymer; $T_{\mathrm{g} 1}$ and $T_{\mathrm{g} 2}$ are the glass transition temperatures of the respective

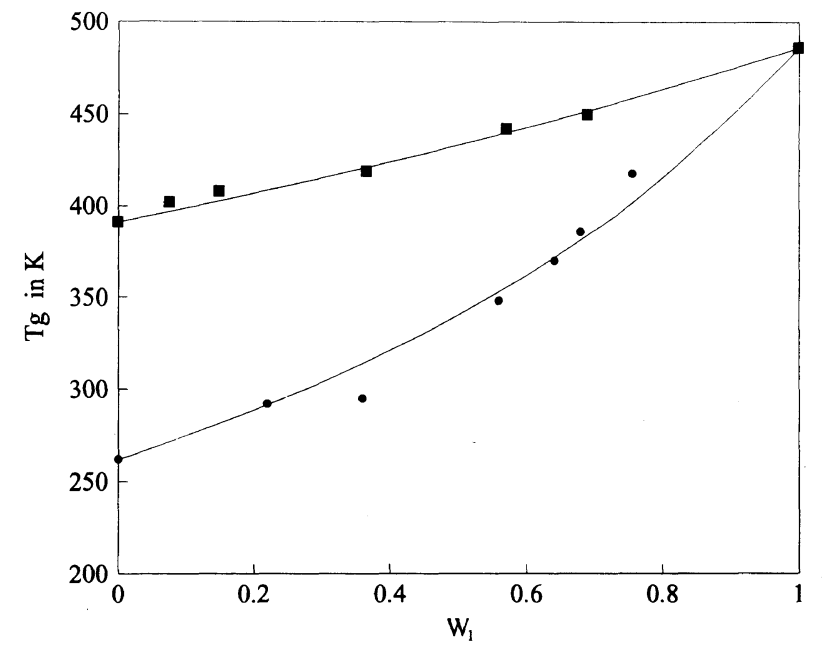

Figure 3. $T_{\mathrm{g}}$ values versus copolymer composition for NVC-MMA (घ) and NVC-MA (O) systems. The solid lines represent the values calculated by the Fox equation.

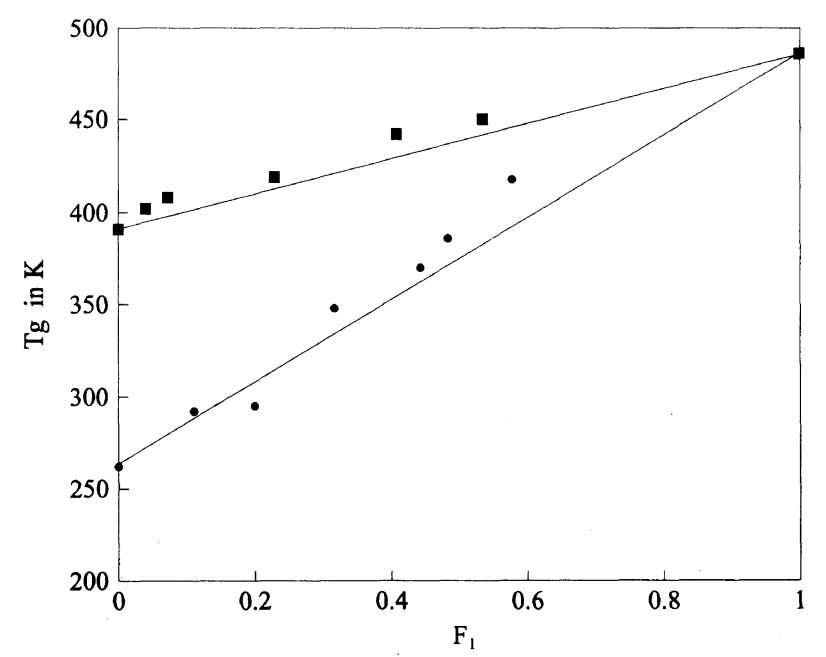

Figure 4. Application of the Di Marzio-Gibbs equation for predicting $T_{\mathrm{g}}$ in function of the copolymer composition; ( $\left.\mathbf{\square}\right)$ : NVC-MMA, experimental values; $(\mathbf{O})$ : NVC-MA, experimental values.

homopolymers. The application of the eq 7 for both systems is shown in Figure 3.

Di Marzio and Gibbs $^{6}$ proposed a simple relation which describes a linear behavior of $T_{\mathrm{g}}$ with copolymer composition:

$$
T_{\mathrm{g}}=F_{1} T_{\mathrm{g} 1}+F_{2} T_{\mathrm{g} 2}
$$

where $F_{1}(\mathrm{NVC})$ and $F_{2}$ (MA, MMA) are mole fractions in the copolymer. The application of eq 8 for our systems is shown in Figure 4.

These theories however, do not take into account the interactions given by the presence of two different monomeric units. In general, it would be expected that the different nature of the comonomers would generate steric and energetic effects when are linked together. Furthermore, the heterolinkages would give different contribution to the rotational barrier and free volume than those of the respective homopolymers. In this sense, there are other theories that also consider the sequence distribution in the copolymer. One example is the model proposed by Johnston, ${ }^{7}$ derived from the Fox theory, which assumes that diads formed by equal monomeric 


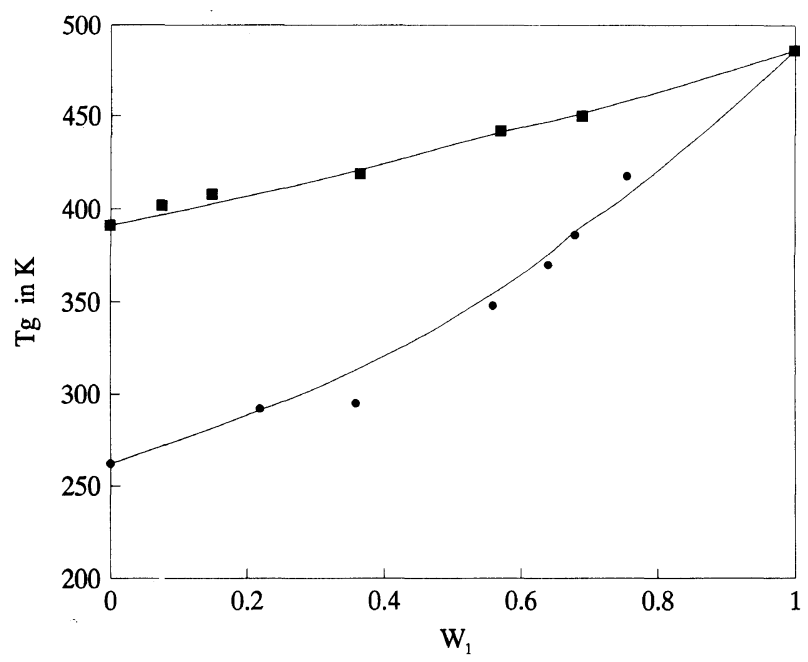

Figure 5. Plot of the glass transition temperatures in function of the copolymers composition according the Johnston theory: ( $\square$ ): NVCMMA, experimental values; (O): NVC-MA, experimental values.

units $1-1$ or 2-2 have the same interactions as those seen in the respective homopolymers. However, the presence of heterodiads will cause new interactions which could modificate the 1 or 2 monomeric unit contribution to the $T_{\mathrm{g}}$ value. Thus, to predict the $T_{\mathrm{g}}$ more accurately, it is necessary to assign their own $T_{\mathrm{g}}$ values for heterodiads. Assuming that 1-2 and 2-1 sequences have the same $T_{\mathrm{g}}$, the following equation can be obtained:

$$
\frac{1}{T_{\mathrm{g}}}=\frac{P_{11} w_{1}}{T_{\mathrm{g} 11}}+\frac{P_{22} w_{2}}{T_{\mathrm{g} 22}}+\frac{P_{12} w_{1}+P_{21} w_{2}}{T_{\mathrm{g} 12}}
$$

where $T_{\mathrm{g} 11}(\mathrm{PNVC})$ and $T_{\mathrm{g} 22}(\mathrm{PMA}, \mathrm{PMMA})$ refer to the homopolymers and $T_{\mathrm{g} 12}$ corresponds to the 1-2, 2-1 diads. $P_{i j}$ is the probability for $i j$ linkages in the chain which can be calculated from the reactivity ratios ${ }^{15}$ :

$$
\begin{gathered}
P_{i j}=\frac{1}{1+r_{i} \frac{[i]}{[j]}} \\
P_{i i}=1-P_{i j}
\end{gathered}
$$

where $[i]$ and $[j]$ are the concentrations of each monomer in the feed.

To apply this theory it is necessary to assign a value to $T_{\mathrm{g} 12}$. These values have been obtained from the experimental data of the $T_{\mathrm{g} 11}, T_{\mathrm{g} 22}$ and the copolymers $T_{\mathrm{g}}$ prepared at low conversions, using the linearized expression of eq 9 . The values were:

$$
\begin{array}{ll}
\text { NVC-MMA system: } & T_{\mathrm{g} 12}=449.6 \mathrm{~K} \\
\text { NVC-MA system: } & T_{\mathrm{g} 12}=383.3 \mathrm{~K}
\end{array}
$$

Figure 5 shows the theoretical dependence of $T_{\mathrm{g}}$ on copolymer composition according to this theory as well as the experimental results obtained. It is observed that in both systems the $T_{\mathrm{g} 12}$ is slightly higher that the mean of the respectively homopolymers glass transition temperatures. This fact would indicate the presence of a positive deviation from the ideal behavior. According to this, weak attractive interactions between comonomers could be expected. Taking into account the electrondonor behavior of the PNVC, these interactions could

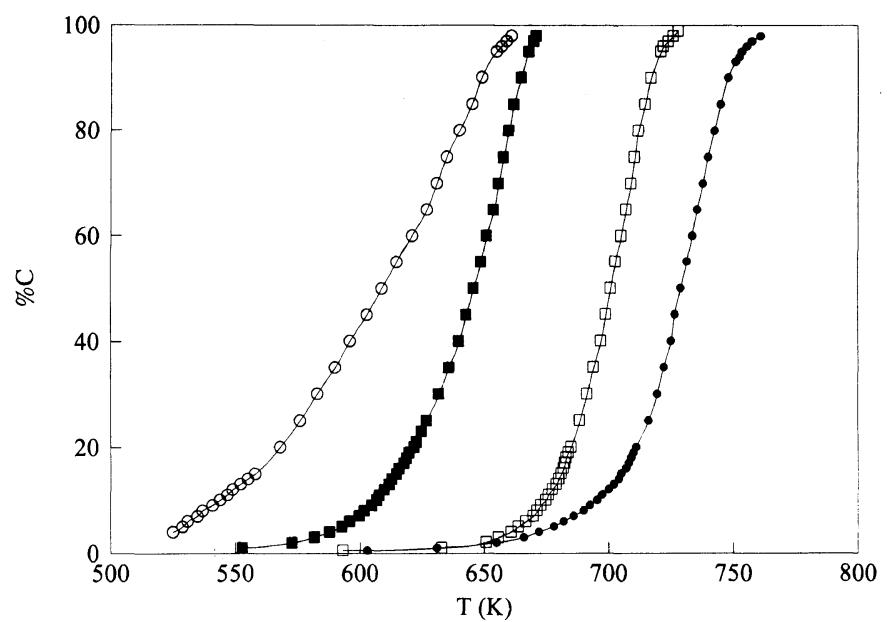

Figure 6. Degradation curves for NVC-MMA system ( $\bigcirc$, PMMA; 口, MMANVC7; $\square$, MMANVC3; , PNVC).

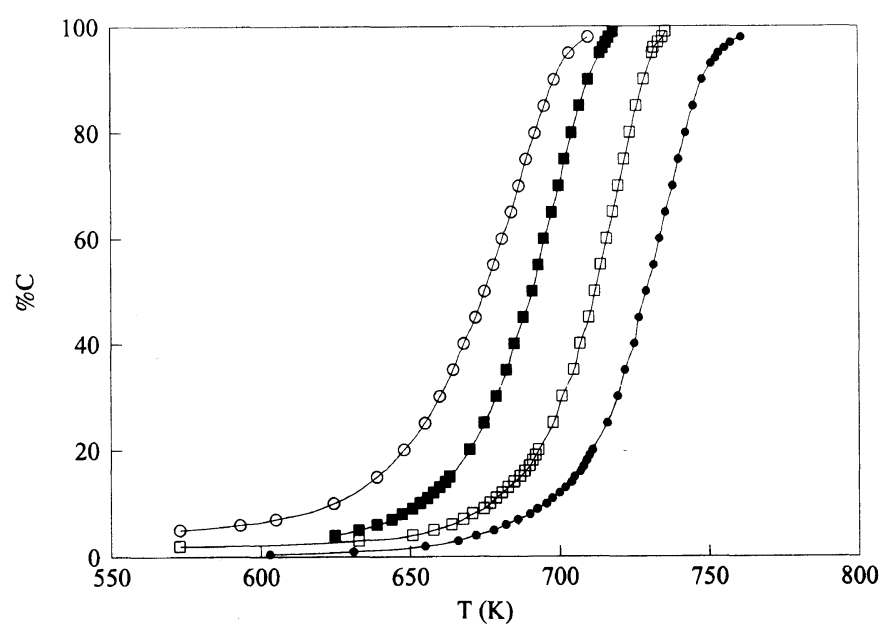

Figure 7. Degradation curves for NVC-MA system (O, PMA; MANVC4; $\square$, MANVC7;, PNVC).

be generated by electrostatic forces between NVC and the respective comonomer. This is more probable in the case of the MA which has a stronger electron-acceptor character than the MMA.

As it can be observed the behavior of the NVCMMA system can be predicted adequately by both the Fox and Johnston's theories. It seems that the consideration of the sequence distribution in the copolymer does not improve the results obtained by the application of the Fox's theory. Only weak interactions will exist between both monomers and as both monomers are bulky, the difference between the rotational barrier associated to the heterolinkages or homolinkages could not have a great influence. In relation to the NVC-MA system, neither of these theories agree with the experimental behavior. Both homopolymers have very different $T_{\mathrm{g}}$ values (above $200 \mathrm{~K}$ ) and therefore, different chain flexibility. It is probable that as the interactions are not so weak, a more accurate consideration of the heterolinkages contribution could be necessary in order to obtain a better theoretical approximation to the experimental behavior.

\section{Thermal stability}

Figures 6 and 7 show the degradation thermograms 
Table III. Degradation of NVC-MMA copolymers (heating rate $=10^{\circ} \mathrm{Cmin}^{-1}$ )

\begin{tabular}{ccccc}
\hline & $\begin{array}{c}\text { Copolymer } \\
\text { comp. }\end{array}$ & & $T_{\mathrm{i}}$ & $E_{\mathrm{a}}$ \\
\cline { 2 - 3 } & mol\% NVC & $\mathrm{K}$ & $\mathrm{kJ} \mathrm{mol}^{-1}$ \\
\hline PMMA & 0 & & \\
MMANVC7 & 4.08 & 685 & 75.42 \\
MMANVC3 & 40.8 & 621 & 137.5 \\
MMANVC4 & 53.5 & 681 & 235.8 \\
PNVC & 100 & 697 & 253.3 \\
\hline
\end{tabular}

Table IV. Degradation of NVC-MA copolymers (heating rate $=10^{\circ} \mathrm{Cmin}^{-1}$ )

\begin{tabular}{ccccc}
\hline \multirow{2}{*}{$\begin{array}{c}\text { Sample } \\
\text { name }\end{array}$} & $\begin{array}{c}\text { Copolymer } \\
\text { comp. }\end{array}$ & & $T_{\mathrm{i}}$ & $E_{\mathrm{a}}$ \\
\cline { 2 - 3 } & mol\% NVC & & $\mathrm{K}$ & $\mathrm{kJ} \mathrm{mol}^{-1}$ \\
PMA & 0 & 635 & 152.5 \\
MANVC4 & 11.1 & 669 & 175.0 \\
MANVC1 & 36.0 & 694 & 127.5 \\
MANVC7 & 44.3 & 701 & 235.8 \\
MANVC6 & 57.8 & 699 & 245.4 \\
PNVC & 100 & 707 & 256.7 \\
\hline
\end{tabular}

for two copolymers and the respective homopolymers at a heating rate of $10^{\circ} \mathrm{Cmin}^{-1}$. The percent mass loss is plotted as a function of temperature where the $100 \%$ mass loss is attained in all cases.

The thermal stability is measured by the onset decomposition temperature, $T_{\mathrm{i}}$, which is calculated as the intersection of the initial baseline with the experimental curve. The obtained values for our systems are shown on Tables III and IV. The hindered interaction of the bulky carbazole group with the main chain makes the thermal stability of PNVC higher than that observed for PMMA or PMA. Furthermore, the both copolymer systems have a high thermal stability which is close to that observed for the PNVC homopolymer at a $50 \%$ by mole of NVC. The activation energy of the degradation process (Tables III and IV) has been obtained for each sample by the McCallum and Tanner's ${ }^{16}$ method. The obtained values for both systems corroborate the high thermal stability observed for the copolymers which increases with increasing the NVC content.

It can be concluded that the introduction of MMA or MA units in the PNVC chain involves a decrease in the glass transition temperature of the system. This fact could facilitate their industrial processing with a relatively small decrease in the thermal stability.

Acknowledgment. Authors would like to thank the University of the Basque Country (UPV/EHU) for the financial support to this project.

\section{REFERENCES}

1. R. C. Penwell, B. N. Ganguly, and T. W. Smith, J. Polym. Sci., Macrom. Rev., 13, 63 (1978).

2. D. M. Chang, S. Gromelski, R. Rupp, and J. E. Mulvaney, J. Polym. Sci., Pol. Chem. Ed., 15, 571 (1977).

3. S. Tazuke, T. Inoue, S. Saito, S. Hirota, and H. Kokado, Polym. Photochem., 6, 221 (1985)

4. D. Bloor, in "Comprehensive Polymer Science," Vol. 2, G. Allen and J. C. Bevington, Ed., Pergamon Press Oxford, 1989.

5. T. G. Fox, Bull. Am. Phys. Soc., 1, 123 (1956).

6. E. A. Di Marzio and J. H. Gibbs, J. Polym. Sci., 40, 121 (1959).

7. N. W. Johnston, J. Macromol. Sci., Rev. Macromol. Chem., C14, 215 (1976)

8. F. R. Mayo and F. M. Lewis, J. Am. Chem. Soc., 66, 1595 (1944).

9. M. Fineman and S. D. Ross, J. Polym. Sci., 5, 259 (1950).

10. T. Kelen and F. Tüdos, J. Makromol. Chem., 183, 619 (1983).

11. S. Curteanu, C. I. Simionescu, and V. Talmacin, Acta Polymerica, 42, 298 (1991).

12. T. Alfrey, J. Polym. Sci., 4, 215 (1949).

13. R. Hart, Makromol. Chem., 47, 143 (1961).

14. A. M. North and K. E. Whitelock, Polymer, 9, 590 (1968).

15. H. J. Harwood and W. H. Ritchey, J. Polym. Sci., 2, 601 (1964).

16. J. R. McCallum and J. Tanner, Eur. Polym. J., 6, 1033 (1970). 